\title{
Um jogo para ensinar Física: A Cinemática de forma lúdica no Ensino Médio
}

\author{
Francisco Alan de O. Santos ${ }^{1}$, Pedro A. Fontes Neto ${ }^{2}$, Alexandre B. dos Santos ${ }^{2}$ \\ ${ }^{1}$ Instituto Federal de Educação do Maranhão - IFMA / Campus Coelho Neto \\ MA-043, s/n - Olho D’Aguinha, CEP 65620-000, Coelho Neto-MA \\ ${ }^{2}$ Instituto Federal de Educação do Maranhão - IFMA / Campus Bacabal \\ Avenida Governador João Alberto, s/n $\mathrm{n}^{\mathrm{o}}$ - Areal, Bacabal-MA \\ \{franciscoalan.santos, pedro.fontes\} @ifma.edu.br, \\ alexandre.barroseacad.ifma.edu.br
}

\begin{abstract}
This paper aims to report the development of a technological prototype in game format to be applied in Physics Teaching. It is intended to apply the prototype among the students entering high school, which generally presented a large gap in Kinematic content. When the educational game is developed, it is expected that a free product will be made available to the general public.
\end{abstract}

Resumo. Este artigo tem como objetivo relatar o desenvolvimento de um protótipo tecnológico em formato de jogo para ser aplicado no Ensino de Física. Pretende-se aplicar o protótipo entre os alunos ingressantes no Ensino Médio, os quais geralmente apresentam grande defasagem de conteúdos de Cinemática. Ao ser desenvolvido o jogo educativo, espera-se a disponibilização de um produto gratuito para o público em geral.

\section{Introdução}

A aprendizagem dos conteúdos da disciplina Física no Ensino Médio e, principalmente, na série inicial, é considerada uma das mais complexas e difíceis para os educandos. Uma possível explicação para essa situação é o fato de muitos alunos não terem contato com a disciplina no final do Ensino Fundamental. A busca por métodos que facilitem a aprendizagem destes conteúdos tem sido constante e alvo de muitos pesquisadores que têm abordado o assunto de formas diversas, como por exemplo, recursos educativos digitais [Quintas; Carvalho 2016], simulações computacionais [Paza et. al. 2016], realidade virtual [Batista Junior] [Silva et. al. 2013], realidade aumentada [Herpich et. al. 2017] e laboratório virtual [Fonseca et. al. 2013]. Jogos também têm sido usados como método de ensino em física [Oliveira et. al. 2004]. Nesse sentido, os jogos para dispositivos móveis são, atualmente, muito usados e populares entre os jovens e adolescentes.

A proposta deste trabalho é desenvolver um jogo para smartphone na plataforma Android que auxilie o ensino e estimule o aprendizado de Física. O diferencial desse jogo para os encontrados na literatura atual é que o mesmo consiste em contextualizar os conceitos e fórmulas da Cinemática dentro de um ambiente virtual imersivo, onde o educando possa aplicar conhecimentos da mecânica física, orientado ao objetivo de 
resolver problemas práticos que simulem situações reais envolvendo movimento, posição, velocidade e aceleração de corpos em um dado instante, proporcionando ao jogador uma experiência aventuresca na qual os obstáculos devem ser trespassados com o seu conhecimento em física.

Neste contexto, este trabalho objetiva desenvolver um jogo educativo que ensine Física de forma lúdica em uma linguagem popular entre os adolescentes, que são os jogos em smartphones Android, e disponibilizá-lo ao público em geral. A ideia central é possibilitar uma ferramenta auxiliar de que gere maior interesse nas aulas e atividades da disciplina de Física, uma vez que o aplicativo tende a estimular o aluno a estudar para ter um bom desempenho no jogo. Para atestar a efetividade da ferramenta, pretende-se realizar uma análise da adoção do jogo como recurso didático em uma turma experimental da $1^{\text {a }}$ série do Ensino Médio, comparando os resultados com uma turma controle em que não será usado o jogo, para verificar a aprendizagem dos conteúdos.

\section{Problematização}

Muito se tem discutido sobre a importância do ensino de Física em todos os níveis de escolaridade. Sabe-se que o acesso ao conhecimento científico se dá de diversas formas, e em diferentes ambientes, mas é na escola que a formação de conceitos científicos são aprofundados e explicados para os discentes, onde a autonomia e autoria pode acontecer e tudo depende do método a ser empregado no contexto escolar [Demo 2009].

Usar jogos como parte de um processo de aprendizagem é um método lúdico que pode motivar o aluno a direcionar a formação do pensamento para a disciplina e mudar suas atitudes durante a aula, passando a ser um sujeito participativo em sala. Porém, desde que o jogo, ao ser disponibilizado, abra espaço para que o aluno seja motivado a pesquisar os conteúdos que o envolvem. De outra forma, o jogo não passaria de uma mera distração cotidiana. Sendo assim, o jogo deve ser um instrumento para contribuir na formação do conhecimento científico de forma crítica e autônoma para que o estudante saiba o que buscar, como buscar e onde buscar o saber científico [Masetto 2010].

Em síntese, este trabalho objetiva mostrar a eficiência do método utilizado para ensinar o aluno a construir o aprendizado com o uso de um jogo educativo, que o estimule na investigação de forma lúdica e eficaz na aquisição de conhecimento, inserindo-o na pesquisa de temas relevantes ao ensino de Cinemática na disciplina Física na $1^{a}$ série do Ensino Médio.

\section{O jogo}

O jogo consiste na jornada de um personagem principal (avatar), que personifica a figura do aluno, que deve solucionar problemas contextualizadas no cenário do jogo. A evolução do conhecimento do aluno se dá pelo seu sucesso ao superar barreiras apresentadas ao longo das fases do jogo. A dinâmica de funcionamento pode ser exemplificada no exemplo a seguir: em um determinado cenário, um personagem andando por uma trilha, se depara com um desafio, para atravessar o obstáculo, o jogador deverá pressionar um botão que acionará uma pergunta sobre cinemática. Se o jogador direcionar o personagem para a resposta correta, o jogo prossegue para a próxima fase, caso contrário, a situação se repete por mais uma quantidade determinada 
de tentativas até que ele acerte ou tenha que recomeçar o jogo ou a fase em que parou. Para os jogadores que chegarem até o fim, as perguntas serão modificadas automaticamente ao se iniciar o jogo ou a fase. Sempre apresentando um tópico novo em cada fase. Assim, o próprio jogo se propõe a ensinar os conteúdos de cinemática da disciplina Física. A Figura 1 ilustra a dinâmica do jogo em sua versão atual.
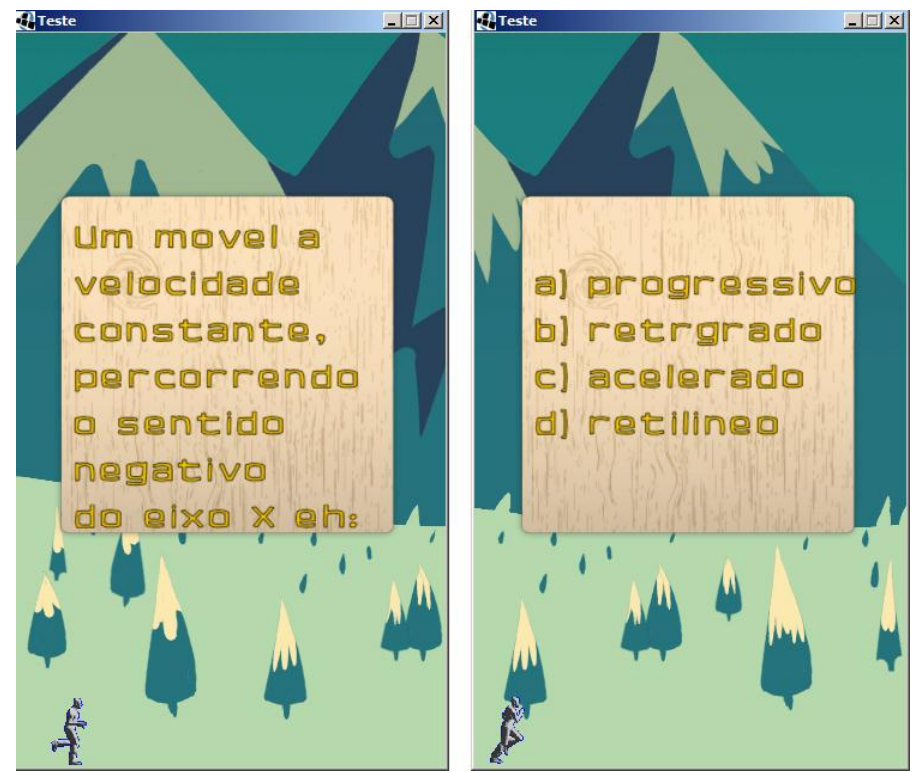

Figura 1. Personagem em frente o desafio

\section{Metodologia}

O trabalho foi inicialmente desenvolvido a partir de uma pesquisa bibliográfica baseada em fontes como livros, artigos e materiais eletrônicos que versam sobre o tema estudado.

Para aplicação do projeto, foi utilizada a linguagem de programação JAVA e a ferramenta de criação de jogos 2D LibGDX, um motor de jogos fornecido gratuitamente, para auxiliar no desenvolvimento de jogos 2D para PC e Android. O critério norteador para escolha desta ferramenta é que nela podem-se encontrar mecanismos de fácil procedimento para desenvolver um jogo para Android, a saber: suporte para a utilização de recursos avançados de entrada de dados, como touchscreen e acelerômetro, bibliotecas de renderização, simulação física e uma assets pipeline. Foi adotada a plataforma Android como ambiente para implantação da versão inicial do jogo. O motivo da escolha desta plataformaa se deu pela sua popularidade entre os alunos na faixa etária alvo do aplicativo.

Atualmente o protótipo está sendo utilizado nas aulas do $1^{\circ}$ módulo, que faz parte $1^{\text {a }}$ série do Ensino Médio de cursos Técnicos Integrados ao Ensino Médio, que será o universo desta pesquisa. Deste universo, será usado uma turma experimental e outra como grupo controle da pesquisa. Estão sendo utilizados como instrumentos de coleta de dados: observações, depoimentos e entrevistas, avaliações e um questionário com perguntas que versão sobre o conhecimento de Cinemática adquirido pelos alunos com o uso do jogo. Os rendimentos na aprendizagem da turma experimental e a de controle serão comparados usando as avaliações aplicadas durante a disciplina. 


\section{Considerações finais}

Este trabalho apresentou uma abordagem de ensino de Física utilizando um protótipo de jogo para dispositivos móveis. Espera-se que com este trabalho haja uma contribuição efetiva para o ensino de Física e que o método seja aproveitado pelos professores da área. Ao ser desenvolvido um jogo educativo que ensine Física, espera-se a disponibilização de um produto gratuito para o público em geral.

Como próximos passos, pretende-se aplicar o protótipo em turmas iniciantes do ensino médio para que corra aprendizagem da disciplina quando o jogo for aplicado em sala de aula e, dessa forma, também haja uma contribuição como fonte bibliográfica para os pesquisadores do ensino de Física.

\section{Referências}

Batista Junior, E. P.; Santos FH,J.V. ; Ferreira, J. S . Utilizando Ambientes virtuais como ferramenta de auxilio no ensino de Fisíca em escolas públicas.. In: $22^{\circ}$ Simpósio Brasileiro de Informática na Educação. 2011, Aracaju. Anais do $22^{\circ}$ do Simpósio Brasileiro de Informática na Educação, 2011.

Demo, P. Educar pela pesquisa. 8. ed. Campinas: Autores Associados, 2009, 106p.

. Metodologia para quem quer aprender. São Paulo: Atlas, 2008,131p.

Fonseca, M. et. al. O laboratório virtual: Uma atividade baseada em experimentos para o ensino de mecânica. Revista Brasileira de Ensino de Física, São Paulo, SP, v. 35, n. 4, p. 1-10 (4503), 2013.

Herpich, F.; Guarese, Renan Luigi Martins ; Tarouco, L. M. R. . Recursos de virtualidade integrados com realidade aumentada em dispositivos móveis para auxiliar estudantes na aprendizagem de física. 2017.

Masetto, M.T. O professor na hora da verdade: a prática docente no ensino superior. São Paulo: Avercamp, 2010, 192p.

Quintas, M. J.; Carvalho, P. S. Ensino interativo na abordagem da eletricidade numa escola portuguesa. Caderno Brasileiro de Ensino de Física, Florianópolis, SC, v. 33, n. 3, p. 839-860, dez. 2016.

Oliveira, Marcos Paulo Salvador de ; Ulson, Roberta Spolon ; Cavenaghi, M. A. ; Marana, Aparecido Nilceu ; Almeida JR, Jurandy Gomes de ; Lobato, Renata Spolon - Ferramenta para Apoio ao Aprendizado de Física Básica. In: 15o. Simpósio Brasileiro de Informática na Educação, 2004, Manaus/AM. Anais do 15o. Simpósio Brasileiro de Informática na Educação, 2004. v. 1.

Paza, A. H.; Rocha, Elizabeth Matos ; Lourenco, A. B. ; Cruz, A. J. A. ; Ferreira, F. C. ; Botero, E. . Simulador computacional para o Ensino de Física: o Sandbox como ambiente de criação. In: V Congresso Brasileiro de Informática na Educação, 2016. Anais dos Workshops do V Congresso Brasileiro de Informática na Educação, 2016.

Silva, Gabriel Caixeta; De Sousa, Pedro Moisés . O uso da realidade virtual para o ensino de física quântica Use of virtual reality in learning of quantum physics. In: Worshops do II Congresso Brasileiro de Informática na Educação, 2013. v. 1. 